Original Article

\title{
ANTI-INFLAMMATORY ACTIVITY OF CURCUMIN AND CAPSAICIN AUGMENTED IN COMBINATION
}

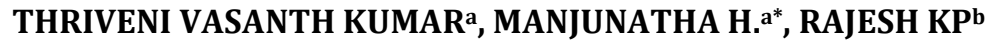 \\ aDepartment of PG Studies and Research in Biotechnology and Bioinformatics, Jnana Sahyadri, Kuvempu University, Shankaraghatta \\ 577451, Shimoga, Karnataka, India, bBiocon Research Centre, Biocon, Bengaluru, Karnataka, India \\ Email: *manjunatha75@gmail.com, thriveni.vv@gmail.com \\ Received: 22 Mar 2017 Revised and Accepted: 29 Apr 2017
}

\section{ABSTRACT}

Objective: Dietary curcumin and capsaicin are well known for their health beneficial potencies. The current study was done to assess the antiinflammatory activity of curcumin, capsaicin and their combination by employing in vitro and in vivo models.

Methods: We investigated the protective effect of curcumin, capsaicin and their combination using in vitro heat induced human red blood cell (HRBC) membrane stabilisation, in vivo 3\% agar induced leukocyte mobilisation and acetic acid induced vascular permeability assay.

Results: Curcumin, capsaicin and their combination exhibited concentration dependent protective effect against heat-induced HRBC membrane destabilisation, while combined curcumin and capsaicin restored $(87.0 \pm 0.64 \%)$ membrane stability and it is found to be better than curcumin, capsaicin and standard diclofenac sodium (75.0 $\pm 0.25 .72 \pm 0.9$ and $80.0 \pm 0.31 \%)$ protective effect. In agar suspension induced leukocyte mobilization assay, the combined curcumin and capsaicin had shown $39.5 \pm 1.58 \%$ of inhibition compared to individual curcumin and capsaicin, which showed moderate inhibition of $16.0 \pm 3.14$ and $21.6 \pm 2.17 \%$ respectively. Besides, the combined curcumin and capsaicin had shown highly significant inhibition of acetic acid-induced vascular permeability in rats $(62.0 \pm 3.14 \%)$, whereas individual curcumin and capsaicin showed moderate inhibition of vascular permeability with $36.0 \pm 2.41$ and $43.0 \pm 1.92 \%$ respectively.

Conclusion: This study demonstrates the significant anti-inflammatory property of combined curcumin and capsaicin at half of the individual concentration of curcumin and capsaicin.

Keywords: Curcumin, Capsaicin, Leukocyte mobilization, Vascular permeability, Human red blood cell membrane

(C) 2017 The Authors. Published by Innovare Academic Sciences Pvt Ltd. This is an open access article under the CC BY license (http://creativecommons.org/licenses/by/4.0/) DOI: http://dx.doi.org/10.22159/ijpps.2017v9i6.18635

\section{INTRODUCTION}

Inflammation is a complex biological response of vascular tissues to harmful stimuli [1]. Upon contact with the stimuli, immune cells undergo activation and release inflammatory mediators such as vasoactive amines and eicosanoids to remodel the local vasculature. These mediators vasodilate and permeabilize the blood vessels causing exudation of blood plasma [2] results in enlarged and dilated blood vessels [3] thereby activation of leukocytes which play an important role in the development, propagation and maintenance of inflammation [4]. These leukocytes move towards the inflamed site or tissue to abet inflammatory response, found to be the essential step of defence against pathogens [5]. At the site of inflammation immune cells abrogate further invasion and multiplication of pathogens by phagocytosis [4] causing the production of several inflammatory mediators, including cytokines/chemokines, degrading enzymes, free radical oxygen and nitrogen species, and metalloproteases amplifying the inflammatory response and injury to surrounding tissues leading to inflammatory related diseases [6-11].

Spices are nutraceuticals which have been used as the predominant class of food adjuncts to enhance the taste, colour and flavor of foods and beverages. Curcumin, the yellow colouring principle of turmeric (Curcuma longa) and Capsaicin, the principle pungent component of red pepper (Capsicum annuum) are naturally occurring active principles. Clinical pharmacological studies on dietary curcumin and capsaicin have been proven to possesses promising health beneficial therapeutic potential such as anti-arthritic [12, 13], antiinflammatory [14, 15], antitumor and anticancer [16-18], antihypoglycemic [19] and lipid-lowering activities [20]. Mechanism of action, which is responsible for the health beneficial pharmacological activity of these two commonly used curcumin and capsaicin have been extensively studied and reported [21-25]. Although these two spice principles share a considerable amount of structural homology nevertheless possesses notable differences in the mechanism of action. Hence, the protective effect of curcumin, capsaicin and their combination against copper/iron-induced lowdensity lipoprotein (LDL) oxidation, the toxicity of iron to liver and carrageenan-induced inflammation in rats was evaluated. The combined curcumin and capsaicin was found to be more effective than individual molecules. In addition, these molecules also shown to have decreased higher level of cholesterol and triglycerides in hypercholesterolemic and hyperlipidemic rats [23, 26]

In view of the above properties, the present study was further aimed at emphasizing the anti-inflammatory influence of combined dietary curcumin and capsaicin in in vivo and in vitro to verify, if any additive/synergistic property being exerted by them. Information on the protective effect of combined curcumin and capsaicin as antiinflammatory agents would be more relevant in the context of the dietary source being used extensively in combination by the peoples around the world.

\section{MATERIALS AND METHODS}

\section{Chemicals}

Dietary curcumin and capsaicin were procured from Sigma-Aldrich. Agarose was procured from GeNei ${ }^{\mathrm{TM}}$ Bangalore, India. EDTA, Diclofenac sodium, Wright's stain, Evans blue, acetic acid solutions were procured from Himedia. All other chemicals used were of analytical grade.

Animals

Male Wistar rats weighing 150-200 g were housed in individual stainless steel cages, maintained on standard pellet diet with ad libitum water. The animals were maintained under controlled conditions of temperature with $12 \mathrm{~h}$ light-dark cycle. The animals were used after an acclimatization period of three days in the laboratory animal house. Animal experiments were carried out 
taking appropriate measures to minimize pain or discomfort in accordance with the guidelines of the animal ethics laid down by the NIH (USA) regarding the care and use of animals for experimental procedures and with due clearance from the Institute's Animal Ethics Committee CPCSEA (Ref: NCP/IAEC/CL/14/12/2010-11).

\section{In vitro anti-inflammatory assay}

\section{Membrane stabilization test}

\section{Preparation of red blood cells (RBCs) suspension}

Fresh whole human blood ( $5 \mathrm{ml}$ ) was collected in a heparinized tube and transferred to the centrifuge tubes. The tubes were centrifuged at $3000 \mathrm{rpm}$ for $10 \mathrm{~min}$ and washed three times with equal volume of normal saline. The volume of blood was measured and reconstituted as $10 \% \mathrm{v} / \mathrm{v}$ suspension with normal saline $[28,29]$.

\section{Heat-induced hemolytic assay}

The reaction mixture $(2 \mathrm{ml})$ consisting of $1 \mathrm{ml}$ of sample/diclofenac sodium at different concentration and $1 \mathrm{ml}$ of $10 \%$ RBCs suspension, parallel control was maintained under optimum conditions. The reaction mixture was incubated in water bath at $56{ }^{\circ} \mathrm{C}$ for $30 \mathrm{~min}$. At the end of incubation, the tubes were cooled to room temperature. The reaction mixture was centrifuged at $2500 \mathrm{rpm}$ for $5 \mathrm{~min}$ and the absorbance of the supernatant was measured at $560 \mathrm{~nm}$. Percent membrane stabilization activity was calculated by using the following formula $[29,30]$.

$$
\text { Percent membrane stabilization }=\left[\frac{\mathrm{As}-\mathrm{Ac}}{\mathrm{Ac}}\right] \times 100
$$

Where, as and Ac represents the absorbance of sample and control, respectively.

\section{In vivo anti-inflammatory assay}

\section{Animal treatment}

Male Wistar rats (6 per group) weighing 150-200 g were acclimatized for three days and then they were divided into 5 groups (A to $\mathrm{F}$ ) as mentioned below.

Group A: Normal control (Normal saline)

Group B: Vehicle control (Olive oil)

Group C: Curcumin (100 mg/kg, p. o)

Group D: Capsaicin (30 mg/kg, p. o)

Group E: Combined curcumin and capsaicin (50 mg/kg curcumin+15 $\mathrm{mg} / \mathrm{kg}$ capsaicin, p. o)

\section{Group F: Diclofenac sodium (50 mg/kg, p. o standard drug)}

The doses of curcumin and capsaicin were chosen on the basis of previous studies [31,32].

\section{Vascular permeability test in rats}

The effect of individual and combined curcumin and capsaicin on acetic acid induced vascular permeability assay was assessed by a modified method of Whittles [33]. The animals were kept fasting for $10 \mathrm{~h}$ prior to the experiment and then administered suspension of normal saline, diclofenac sodium, curcumin, capsaicin and combined curcumin and capsaicin orally. After $3 \mathrm{~h}$, all the groups were administered with $0.5 \mathrm{ml}$ of $1 \%$ Evans blue solution (i. v), vascular permeability was induced by intraperitoneal injection of $1 \mathrm{ml}$ of $0.6 \%$ acetic acid. Upon administration, the animals were left at room temperature for $20 \mathrm{~min}$. Later, the animals were sacrificed under light ether anaesthesia and peritoneum was washed with $10 \mathrm{ml}$ of normal saline and collected. The peritoneal fluid was centrifuged and the absorbance of the supernatant was observed at $610 \mathrm{~nm}$. The percentage inhibition of vascular permeability was calculated using the formula:

$$
\text { Percentage inhibition of permeability }=\left[1-\left(\frac{T}{C}\right) \times 100\right]
$$

Where $\mathrm{T}$ and $\mathrm{C}$ represent the absorbance measurements of the treated and control groups respectively.

\section{Leukocyte mobilization test in rats}

The protective effect of individual and combined curcumin and capsaicin on $3 \%$ agar induced in vivo leukocyte mobilization was evaluated by using the method of Rebeiro et al. [5]. After oral administration of normal saline, diclofenac sodium drug, curcumin, capsaicin and combined curcumin and capsaicin to respective groups, animals were left at room temperature for $3 \mathrm{~h}$. Later, all the groups except parallel control were administered $0.5 \mathrm{ml}$ of $3 \% \mathrm{w} / \mathrm{v}$ agar suspension (i. p) in normal saline. Four hours later, the animals were sacrificed under light ether anaesthesia and the peritoneal cavities were washed with $5 \mathrm{ml}$ of 5\% EDTA in phosphate buffered saline (PBS). The peritoneal fluid was recovered and subjected for total and differential leukocyte counts (TLC and DLC) using perfusates by following the manual cell counter after staining with Wright's stain. The percentage inhibition of leukocyte migration was calculated using the following formula:

Percentage inhibition of leukocyte mobilization $=\left[1-\left(\frac{T}{C}\right) \times 100\right]$

Where $\mathrm{T}$ and $\mathrm{C}$ represent the leukocyte count of treated and control groups respectively.

\section{Statistical analysis}

All the experiments were performed in triplicate and results were recorded as mean $\pm S D$ (standard deviation). Statistical analysis was performed using one-way ANOVA followed by Dunnett's multiple comparison tests. Data was computed for statistical analysis by using Graph Pad prism 5 (San Deigo, CA). The values of $\mathrm{p}<0.05$, $\mathrm{p}<0.01$ were considered as statistically significant.

\section{RESULTS AND DISCUSSION}

Protective effect of dietary curcumin, capsaicin and their combination on heat induced HRBC membrane stabilization

Erythrocytes, most commonly and abundantly available cells of the human body and possess desirable physiological and morphological characteristics, hence used extensively as biological models [34]. Exposure of red blood cells (RBCs) to injurious substances results in the lysis of the membranes, accompanied by hemolysis and oxidation of hemoglobin [35]. During inflammation, lysosomes undergo lysis, as a result, they release enzymes producing a variety of implications [36]. Since lysosomal membrane components resemble human red blood cell (HRBC) membrane components [37], thereby HRBC were employed in the study.

The inhibition of heat induced human red blood cell membrane lysis was taken as a measure of the mechanism of anti-inflammatory activity of individual and combined curcumin and capsaicin. 100\% lysis was observed when the HRBC membrane was heat incubated; increasing temperature could cause decreased osmotic fragility [38] and change the intracellular metabolism and perturbation of membrane structure [39]. Nevertheless, the stability of heat incubated membrane integrity was consistently maintained by curcumin, capsaicin and their combination including standard diclofenac sodium as shown in fig. 1. Curcumin, capsaicin and their combination along with standard diclofenac sodium have shown dosedependent protective activity against heat-induced lysis of HRBC membrane. Mechanism of curcumin has indicated that it is reported to be aggregating at relatively high concentration, within the lipid bilayer of the membrane [40]. While the capsaicin was able to enter and align with the phospholipid bilayer of the membrane. Membrane stabilization activity of curcumin and capsaicin at $50 \mu \mathrm{g} / \mathrm{ml}$ concentration was found to be $75.0 \pm 0.25$ and $72 \pm 0.9$ respectively. These results are in agreement with the previous reports of Arnab et al. [41], where they have shown concentration dependant protective activity of curcumin against 2, 2'-azobis (2-amidinopropane) hydrochloride-induced hemolysis of HRBCs. Similarly, capsaicin has also shown a dose-dependent protective effect against the osmotic fragility of human erythrocytes, at $10^{-4}$ and $10^{-5} \mathrm{M}$ [2]. However, combined curcumin and capsaicin have shown $(25 \mu \mathrm{g} / \mathrm{ml}+25$ $\mu \mathrm{g} / \mathrm{ml}) 87.0 \pm 0.64 \%$ activity, which is more significant than 
individual molecules and standard diclofenac sodium $(80.0 \pm 0.31$ at $50 \mu \mathrm{g} / \mathrm{ml}$ ). Increased membrane stabilization effect of combined curcumin and capsaicin may be due to the facilitating effect of capsaicin in overcoming the mere aggregation of curcumin on the membrane surface by perturbing the packing of lipids and affecting the thermo tropic properties inside the cell.

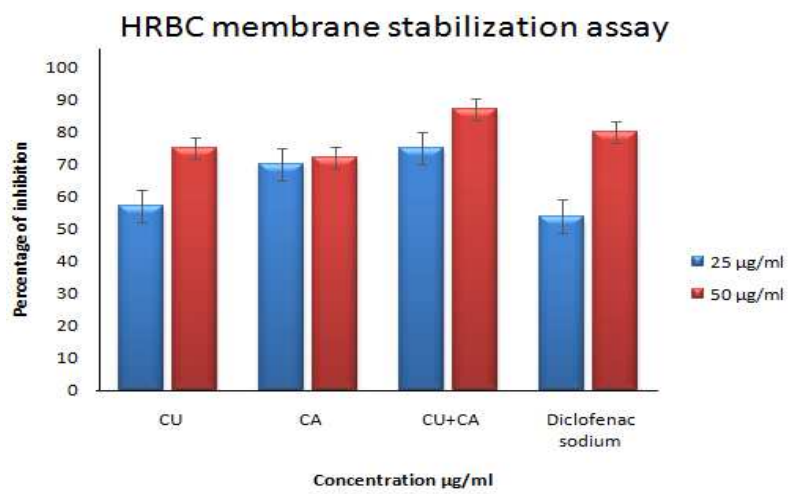

Fig. 1: Protective effect of curcumin, capsaicin and their combination on in vitro heat-induced lysis of human red blood cell membrane. Data is expressed as mean $\pm S D[n=3]$
Protective effect of dietary curcumin, capsaicin and their combination on acetic acid induced vascular permeability test in rats

Intraperitoneal injection of acetic acid induces dilation of blood vessels and this was evidenced by the leakage of Evans blue dye into the peritoneum cavity across the blood vessels including epithelial membrane results in the coloration of peritoneum fluid. The influence of dietary curcumin, capsaicin and their combination on vascular permeability induced by acetic acid in rats is presented in table 1 . Dietary curcumin and capsaicin have shown $36.0 \pm 2.41$ and $43.0 \pm 1.92$ percent inhibition of acetic acid-induced vascular permeability.

A study by Saowanee et al. [42] reported that, oral administration of 50 and $100 \mathrm{mg} / \mathrm{kg} /$ day of curcumin for $3 \mathrm{w}$ increased antioxidant and vascular protective effect on hypertension induced rats. Similarly, Jancso et al. [43] also reported that the local vasodilation and increased vascular permeability generated by the activation of sensory neurons was downregulated as well as reduced antidromic vasodilation in animals pretreated with capsaicin [44]. Combined curcumin and capsaicin exhibited significant inhibition of vascular permeability compared with curcumin and capsaicin, where the percentage inhibition of vascular permeability was $62.0 \pm 3.14$ $(\mathrm{p}<0.001)$ and comparable with the diclofenac sodium $(66.0 \pm 4.08)$ Specifically, an additive effect was seen when curcumin and capsaicin were fed in combination.

Table 1: Effect of dietary curcumin, capsaicin and their combination on acetic acid induced vascular permeability in rats

\begin{tabular}{llll}
\hline Treatment groups & Dose $(\mathbf{m g} / \mathbf{k g})$ & Absorbance & \% inhibition \\
\hline Control & - & $0.77 \pm 0.09$ \\
Curcumin & 100 & $0.49 \pm 0.03^{* *}$ & - \\
capsaicin & 30 & $0.44 \pm 0.07^{* * *}$ & $36.0 \pm 2.41$ \\
Curcumin and capsaicin & $50+15(1: 1)$ & $0.29 \pm 0.08^{* * *}$ & $43.0 \pm 1.92$ \\
Indomethacin & 50 & $0.26 \pm 0.12^{* * *}$ \\
\hline
\end{tabular}

Data is expressed as mean $\pm \mathrm{SD}[\mathrm{n}=6]$, Values are performed using one-way ANOVA followed by Dunnett's multiple comparison tests. The values of ${ }^{*} \mathrm{p}<0.05,{ }^{* *} \mathrm{p}<0.01$ and ${ }^{* * *} \mathrm{p}<0.001$ were considered as statistically significant.

Protective effect of dietary curcumin, capsaicin and their combination on agar induced leukocyte mobilization test in rats

The protective effect of curcumin, capsaicin and their combination on $3 \%$ agar induced leukocyte mobilization in the peritoneal cavity of rats was evaluated (table 2). Increased level of total leukocyte counts predominated by neutrophils was noticed in the peritoneum fluid collected from the agar induced rats. Whereas, curcumin, capsaicin and their combination have shown significant inhibition of leukocyte mobilization at the percentage of $16.0 \pm 3.14,21.6 \pm 2.17$ and $39.5 \pm 1.58$ respectively. Nevertheless, diclofenac sodium (50 $\mathrm{mg} / \mathrm{kg} \mathrm{b.} \mathrm{w}$ ) treated group has shown $40.0 \pm 1.92$ percent inhibition of leukocyte mobilization. However, half of the concentration of individual molecules in their combination has shown synergistic activity and it was almost comparable with that of the standard drug.

Our report is in agreement with Moghaddam et al. [45] who demonstrated that oral supplementation of dietary curcumin results in a marked reduction of total leukocyte and neutrophil counts induced by extrinsic and intrinsic inflammatory models in a dosedependent manner in mice and Francis et al. [46] stated that administration of curcumin by intraperitoneal injection $3 \mathrm{~h}$ prior to lipopolysaccharide (LPS) injection into the air pouch cavities for $6 \mathrm{~h}$ resulted in the $50 \%$ inhibition of total leukocytes accumulation.

Table 2: Effect of dietary curcumin, capsaicin and their combination on agar induced leukocyte mobilization in rats

\begin{tabular}{|c|c|c|c|c|c|c|c|}
\hline \multirow[t]{2}{*}{ Treatment groups } & \multirow[t]{2}{*}{ Dose (mg/kg) } & \multirow[t]{2}{*}{ TLC $\times 10^{9}$} & \multirow[t]{2}{*}{ \% inhibition } & \multicolumn{4}{|c|}{ Differential leukocyte mobilization (\%) } \\
\hline & & & & Neutrophils & Lymphocytes & Eosinophils & Monocytes \\
\hline Control & - & 18.30 & - & 70.66 & 28.33 & 1.33 & 0.66 \\
\hline Curcumin & 100 & $15.40^{*}$ & $16.0 \pm 3.14$ & 59.66 & 38.00 & 1.66 & 0.66 \\
\hline Capsaicin & 30 & $14.36^{* *}$ & $21.6 \pm 2.17$ & 58.00 & 38.66 & 1.33 & 2.0 \\
\hline Curcumin+capsaicin & $50+15$ & $11.08^{* * *}$ & $39.5 \pm 1.58$ & 58.00 & 38.66 & 1.34 & 2.0 \\
\hline Diclofenac sodium & 50 & $10.72^{* * *}$ & $40.0 \pm 1.92$ & 60.75 & 36.5 & 1.25 & 1.5 \\
\hline
\end{tabular}

Data is expressed as mean $\pm \mathrm{SD}[\mathrm{n}=6]$, Values are performed using one-way ANOVA followed by Dunnett's multiple comparison tests. The values of ${ }^{*} \mathrm{p}<0.05,{ }^{* *} \mathrm{p}<0.01$ and ${ }^{* * *} \mathrm{p}<0.001$ were considered as statistically significant.

\section{CONCLUSION}

Taken together, the present in vitro and in vivo studies demonstrate that the dietary intake of combined curcumin and capsaicin can suppress the heat induced in vitro HRBC membrane lysis, acetic acid-induced in vivo vascular permeability and agar induced in vivo leukocyte mobilization in a rat model. However, further biochemical and molecular studies will be necessary to reveal the molecular mechanisms by which these two commonly used combined dietary curcumin and capsaicin function in vivo.

\section{ACKNOWLEDGEMENT}

This work was supported by a grant from Department of Science and Technology-Science and Engineering Research Board (DST-SERB) (SB/EMEQ-343/2013), Govt. of India, New Delhi. First author (Thriveni V) thanks, DST (SERB) for Junior Research Fellowship. The second author (H. Manjunatha) express sincere thanks to DST for funding under the program "Empowerment and Equity Opportunities for Excellence in Science". 


\section{AUTHORS CONTRIBUTION}

1. Thriveni Vasanthkumar: As a first author involved in designing of the work, Data collection, data analysis and data interpretation and drafting of the article.

2. Manjunatha $\mathrm{H}$ : As a co-author involved in the planning of the experiment, data interpretation and critical revision of the article.

3. Rajesh KP: As a co-author supported in the revision of the article.

\section{CONFLICTS OF INTERESTS}

Authors declare that there are no conflicts of interest

\section{REFERENCES}

1. Ferrero-Miliani L, Nielson OH, Andersen PS, Girardin SE. Chronic inflammation: the importance of NOD2 and NALP3 in an interleukin-1ß generation. Clin Exp Immunol 2007;147:227-35.

2. Syed Ibrahim Rizvi, Prem PS. Protective effect of capsaicin on the osmotic fragility of human erythrocytes. Indian J Exp Biol 1999;37:835-6

3. Chaitanya R, Sandhya S, David B, Vinod KR, Murali S. HRBC membrane stabilizing property of root, stem and leaf of Glochidion velutinum. Int J Res Pharm Biomed Sci 2011;4:256-9.

4. Todar K. Immune defence against bacterial pathogens: innate immunity. Todar's online textbook of bacteriology; 2008.

5. Rebeiro RA, Flores CA, Cunha FQ, Ferreira SH. IL-8 causes in vivo neutrophil migration by a cell-dependent mechanism. Immunology 1991;73:472-7.

6. Kasama T, Miwa Y, Isozaki T, Odai T, Adachi M, Kunkel SL. Neutrophil-derived cytokines: potential therapeutic targets in inflammation. Curr Drug Targets Inflamm Allergy 2005;4:273-2.

7. Cattani F, Gallese A, Mosca M, Buanne P, Biordi L, Francavilla S, et al. The role of CXCR2 activity in the contact hypersensitivity response in mice. Eur Cytokine Netw 2006;17:42-8.

8. Palmer G, Gabay C, Imhof BA. Leukocyte migration to rheumatoid joints: enzymes take over. Arthritis Rheum 2006;54:2707-10

9. Tanaka D, Kagari T, Doi H, Shimozato T. Essential role of neutrophils in anti-type II collagen antibody and lipopolysaccharide-induced arthritis. Immunology 2006;119:195-202.

10. Kim ND, Chou RC, Seung E, Tager AM, Luster AD. A unique requirement for the leukotriene B4 receptor BLT1 for neutrophil recruitment in inflammatory arthritis. J Exp Med 2006;203:829-35.

11. Eyles JL, Roberts AW, Metcalf D, Wicks IP. Granulocyte colonystimulating factor and neutrophiles-forgotten mediators of inflammatory disease. Nat Clin Pract Rheumatol 2006;2:500-10.

12. Shehzad A, Rehman G, Lee YS. Curcumin in inflammatory diseases. Biofactors 2013;39:69-77.

13. Matucci Cerinic M, McCarthy G, Lombardi A, Pignone A, Partsch G. Neurogenic influences in arthritis: potential modification by capsaicin. J Rheumatol 1995;22:1447-9.

14. Shin YH, Namkoong E, Choi S, Bae JS, Jin M. Capsaicin regulates the NF-kappa-B pathway in salivary gland inflammation. J Dent Res 2013;92:547-52.

15. Karaman M, Firinci F, Cilaker S, Uysal P, Tugyan K. Antiinflammatory effects of curcumin in a murine model of chronic asthma. Allergol Immunopathol 2012;40:210-4.

16. Beltran J, Ghosh AK, Basu S. Immunotherapy of tumors with neuroimmune ligand capsaicin. J Immunol 2007;178:326-4.

17. Yu J, Peng Y, Wu LC, Xie Z, Deng Y. Curcumin down-regulates DNA methyltransferase 1 and plays an anti-leukemic role in acute myeloid leukemia. PLOS One 2013;8:e55934.

18. Amruthraj NJ, Preetam Raj JP, Saravanan S, Antoine Lebel L. In vitro studies on the anticancer activity of capsaicinoids from Capsicum chinense against human hepatocellular carcinoma cells. Int J Pharm Pharm Sci 2014;6:254-8.

19. Honnalagere RP, Sharada AC. Antioxidant and hypoglycemic effects of curcumin pyrazole derivatives. Int J Pharm Pharm Sci 2015; 7:244-9.

20. Srinivasan K. Dietary spices as beneficial modulators of lipid profile in conditions of metabolic disorders and diseases. Food Funct 2013;4:503-21.
21. Ahuja KD, Kunde DA, Ball MJ, Geraghty DP. Effects of capsaicin, dihydrocapsaicin and curcumin on copper-induced oxidation of human serum lipids. J Agric Food Chem 2006;54:6436-9.

22. Joe B, Vijaykumar M, Lokesh BR. Biological properties of curcumin-cellular and molecular mechanisms of action. Crit Rev Food Sci Nutr 2004;44:97-111.

23. Joe B, Lokesh BR. Effect of curcumin and capsaicin on arachidonic acid metabolism and lysosomal enzyme secretion by rat peritoneal macrophages. Lipids 1997;32:1173-80.

24. Kempaiah RK, Srinivasan K. Influence of dietary curcumin, capsaicin and garlic on the antioxidant status of red blood cells and the liver in high-fat-fed rats. Ann Nutr Metab 2004;48:314-20.

25. Hussain MS, Chandrasekhara N. Biliary proteins from the hepatic bile of rats fed curcumin or capsaicin inhibit cholesterol crystal nucleation in supersaturated model bile. Indian J Biochem Biophys 1994;31:407-12.

26. Manjunatha H, Srinivasan K. Protective effect of dietary curcumin and capsaicin on induced oxidation of low-density lipoprotein, iron induced hepatotoxicity and carrageenaninduced inflammation. FEBS J 2006;273:4528-37.

27. Manjunatha H, Srinivasan K. Hypolipidemic and antioxidant effects of dietary curcumin and capsaicin in induced hypercholesterolemic rats. Lipids 2007;42:1133-42.

28. Sadique J, Al-Rqobah NA, Bughaith MF, El-Gindy AR. The bioactivity of certain medicinal plants on the stabilization of RBC membrane system. Fitoterapia LX; 1989. p. 525-32.

29. Sakat S, Juvekar AR, Gambhire MN. In vitro antioxidant and anti-inflammatory activity of methanol extract of Oxalis corniculata Linn. Indian J Pharm Sci 2010;2:146-55.

30. Shinde UA, Phadke AS, Nari AM, Mungantiwar AA, Dikshit VJ, Saraf MN. Studies on the anti-inflammatory and analgesic activity of Cedrus deodara (Roxb.) loud. Wood oil. J Ethnopharmacol 1999;70:251-7.

31. Suresh D, Srinivsan K. Tissue distribution and elimination of capsaicin, piperine and curcumin following oral intake in rats. Indian J Med Res 2010;131:682-91.

32. Morgana RG, Sabrina GA, Leila SC, Luis CS, Keith LK, Carlos RJ. Curcumin modulates the immune response associated with LPS-induced periodontal disease in rats. Innate Immunity 2010;18:155-63.

33. Whittle BA. The use of changes in capillary permeability in mice to distinguish between narcotic and non-narcotic analgesics. Br J Pharmacol 1964;22:246-53.

34. Hamidi H, Tajerzadeh H. Carrier erythrocytes: an overview. Drug Delivery 2003;10:9-20.

35. Feirrali M, Signormi C, Ciccolili L, Comporti M. Iron release and membrane damage in erythrocytes exposed to oxidizing agents, phenylhydrazine, devicene and iso-uranil. Biochem J 1992;285:295-301.

36. Cooper GM. The cell: a molecular approach. $2^{\text {nd }}$ ed. Bookshelf ID: NBK9953; 2000.

37. Mounnissamy VM, Kavimani S, Balu V, Drlin QS. Evaluation of anti-inflammatory and membrane stabilizing properties of ethanol extract of Canjera rehedi. Iranian J Pharmacol Ther 2008;6:235-7.

38. Aloni B, Eitan A, Livne A. The erythrocyte membrane site for the effect of temperature on osmotic fragility. Biochim Biophys Acta 1977;465:46-53.

39. Hillman RS, Finch CA. Red cell manual. $7^{\text {th }}$ ed. Philadelphia: FA Davis; 1996. p. 58.

40. Loverde SM. Molecular simulation of the transport of drugs across model membranes. J Physical Chem Lett 2014;5:1659-65.

41. Arnab B, Kunwar A, Mishra B, Priyadarsini KI. Concentrationdependent antioxidant/pro-oxidant activity of curcumin studies from AAPH induced hemolysis of RBCs. Chem Biol Interact 2008;174:134-9.

42. Saowanee N, Upa K, Poungrat P, Wanida D, Veerapol K, Bunkerd K, et al. Antioxidant and vascular protective effects of curcumin and tetrahydro curcumin in rats with L-NAME-induced hypertension. Naunyn-Schmiedeberg's Arch Pharmacol 2011;383:519-29.

43. Jancso G, Kiraly E, Jancso GA. Pharmacologically induced selective degeneration of chemosensitive primary sensory neuron. Nature (London) 1977;270:741-3. 
44. Lembeck F, Holzer P. Substance P as a neurogenic mediator of antidromic vasodilation nd neurogenic plasma extravasation. Naunyn Schmiedeberg's Arch Pharmacol 1979;310:175-83.

45. Moghaddam SJ, Barta P, Mirabolfathinejad SG, Ammar AZ, Torres GN, Vo TT, et al. Curcumin inhibits COPD-like airway inflammation and lung cancer progression in mice. Carcinogenesis 2009;30:1949-56.
46. Francis A, Jean CS, Denis G. Curcumin inhibits agent-induced human neutrophil functions in vitro and lipopolysaccharideinduced neutrophil infiltration in vivo. Int Immunopharmacol 2013;17:1101-7.

\section{How to cite this article}

- Thriveni vasanthkumar, Manjunatha H, Rajesh KP. Antiinflammatory activity of curcumin and capsaicin augmented in combination. Int J Pharm Pharm Sci 2017;9(6):145-149. 